\title{
Mais que fait donc la FMH?
}

La question est sur toutes les lèvres.

«Comment? Pas de réaction virulente, pas de campagne de presse? Pourtant, la situation est critique!» Certes.

La réponse est à trouver du côté de la chirurgie:

On incise un abcès quand il est mûr. Ni avant, ni après.

Déterminer le moment favorable (cher à Hippocrate) est un exercice essentiel et périlleux. C'est justement ce que fait la FMH avec tous ses rouages.

Etre prêts à inciser le moment venu.

Encore faut-il identifier l'abcès, afin d'éviter de guerroyer contre des moulins à vents!

Pour vous, lecteurs et lectrices, où se situe l'abcès?

Docteur Claude Aubert, membre du CC de la FMH 